\title{
PERVIVENCIA O "SUPERVIVENCIA" DE LA TRADICIÓN EN EL GUADARRAMA SEGOVIANO. PROCESOS Y PRÁCTICAS ${ }^{1}$
}

\author{
Luis Carlos Martínez Fernández \\ Departamento de Geografía. Universidad de Valladolid \\ luiscar@fyl.uva.es \\ Ignacio Molina de la Torre \\ Departamento de Geografía. Universidad de Valladolid \\ imolina@fyl.uva.es \\ José María Delgado Urrecho \\ Departamento de Geografía. Universidad de Valladolid \\ jose@fyl.uva.es
}

\section{RESUMEN}

El aprovechamiento ganadero es el factor dominante de la organización del espacio en el Guadarrama segoviano. Si bien, desde el decenio de 1950, la actividad pecuaria empieza a entrar en un declive prolongado, reduciéndose el número de explotaciones y la cuantía de cabezas de ganado. Un abandono de las prácticas pastoriles que se evidencia, igualmente, en la inexorable tendencia hacia la simplificación en el manejo de los animales y la utilización selectiva del suelo. Sucede, de este modo, la crisis del sistema tradicional y del modelo territorial en el que este se apoyaba, progresivamente sustituido por una organización geográfica de corte tradicional-degradado. Es, en definitiva, lo que se ha convenido en titular como la "supervivencia" de la tradición. Y cuyo correlato se encuentra en el prolongado proceso de despoblación acontecido desde entonces, como las sensibles mermas de población registradas, las perceptibles modificaciones habidas en el tamaño y número de asentamientos o el excesivo grado de envejecimiento terminan por demostrar. Una "supervivencia" completamente supeditada, de este modo, al agotamiento social.

Palabras clave: Espacio tradicional; desorganización territorial; ganadería; despoblación; Sierra de Guadarrama (Segovia).

\section{ABSTRACT \\ Continuity or "survival" of tradition in the Guadarrama mountain range (Segovia). Processes and practices}

Livestock farming is the predominant factor of spatial organization in the Guadarrama mountain range (Segovia), although cattle activity has been in a long decline since the 1950s. The numbers of farms and livestock have decreased and the handling of animals and land use have been simplified. A crisis occurred in the traditional system and its territorial model, and this has been replaced by a traditional-degraded spatial organization. It is the "survival" of tradition, which can also be seen in the long process of depopulation: the number of inhabitants, the size of the villages and the number of settlements have decreased, while the age of the population has increased. Thus, "survival" is conditioned by population depletion.

\footnotetext{
1 Este artículo forma parte de los resultados del proyecto de investigación: Diseño de un sistema de localización de fotografías aéreas históricas (España). Aplicaciones a la docencia, la investigación, el planeamiento, la ordenación del territorio y los estudios de paisaje (CSO2012-32428), financiado por el Ministerio de Economía y Competitividad, y cuyo investigador principal es Felipe Fernández García.
} 
Keywords: Traditional space; territorial disorganization; livestock; depopulation; Guadarrama mountain range (Segovia, Spain).

\section{INTRODUCCIÓN: LA (DES)ORGANIZACIÓN DEL ESPACIO SERRANO TRADICIONAL}

Viene siendo un lugar común en la literatura académica sobre las áreas de montaña españolas el señalar cómo el proceso de construcción histórica de los espacios rurales de montaña se vio, en términos generales, interrumpido a partir del primer tercio del siglo XIX, sucediéndose desde ese momento un conjunto de hechos y circunstancias que concluirían con la quiebra del modelo histórico de funcionamiento de la montaña. Entre estos hechos y circunstancias cabe destacar, en primer lugar, las modificaciones derivadas de los cambios en las unidades administrativas y de la implantación de un nuevo modelo económico y territorial, con lo que ello implicó de transformaciones en la organización administrativa, de alteraciones en la titularidad jurídica de los recursos y modificaciones en su gestión o de cambios en la organización económica del territorio. Y, en segundo lugar, la pérdida del modelo de organización espacial y la transformación del paisaje heredado consecutivas al despoblamiento de la montaña acontecido a partir del comedio de la pasada centuria. En este encuadre teórico es en el que cabe proceder al entendimiento de las causas que provocaron la progresiva desorganización del espacio serrano tradicional, también las que en el tiempo se sucedieron motivando la pervivencia de este, y más incluso su "supervivencia", operada a través de un modelo de organización tradicional degradado en franco declinar actual.

Esta es la línea argumental y tesis planteada por Ortega Valcárcel en una aportación, ya clásica, a la interpretación del modelo económico y territorial de las ámbitos montañosos de nuestro país (Ortega, 1989). Un concepto, el de la "supervivencia", entendido en el sentido en el que igualmente vuelve a ser utilizado por este autor años más tarde (Ortega, 2004). Y es, también, el hilo discursivo de los trabajos desarrollados en el seno del equipo de investigación dirigido por Delgado Viñas y Plaza Gutiérrez en torno a la Dinámica socioeconómica y articulación espacial de las áreas de montaña de España. Experiencias y orientaciones para el desarrollo sostenible y la cohesión territorial².

Son aportaciones en sintonía con un bagaje de episteme geográfica mucho más amplio, pero en ellas se encuentran fehacientemente las respuestas al interrogante que hace no mucho se formulaba en una de las monografías más acabadas sobre áreas de montaña (Cassé-Castells, 2001); en una reinterpretación constante de aquella maestra contribución de Pierre Deffontaines (1949) y en sintonía con lo que más cercano a nosotros han venido exponiendo con clarividencia, entre otros, Cabero (2000), CIMA (2005) o Montiel (2003).

En este sentido, dos son las premisas que pueden ser formuladas como hipótesis de partida para abordar este trabajo. La primera, la naturaleza social del objeto de estudio, es decir, la percepción de la montaña como un espacio social; lo que no quiere decir que sea un espacio, obviamente, sin componentes físicos o naturales (Ortega, 2000). La montaña es una construcción social. En un proceso de constante elaboración, además, en diversos contextos sociales y técnicos. De ahí que la segunda premisa pase por afirmar el carácter temporal de dicha construcción territorial. Prácticas sociales y procesos territoriales forman parte de la temporalidad histórica e inscriben la transformación, los cambios, la (des)organización, según la terminología empleada. Unos procesos y prácticas territoriales vinculados a la ruptura con las estructuras geográficas de raigambre histórica, dando lugar al abandono o a la degradación, consustanciales a la pervivencia, o más bien, "supervivencia" de la montaña tradicional3.

El área objeto de atención en este artículo se inscribe en el espacio físico de la Sierra de Guadarrama comprendido por los piedemontes de Pedraza y Segovia y el Guadarrama oriental -los Montes Carpetanos- (Mata y Sanz, 2003). Se trata de un territorio que, desde el punto de vista funcional, ha sido definido como "regresivo" en términos de comportamiento demográfico y dinámica socioeconómica (Troitiño, 1990, p. 117), con el sector agrario en crisis y una cierta readaptación en forma de "presencia creciente" de nuevas actividades, en particular las de índole turístico-residencial (Díaz, 2003, p. 744). Es el signo de

2 Una síntesis de los resulados de este proyecto, financiado con cargo al Programa Nacional de Investigación y desarrollado entre 2007 y 2010, puede encontrarse en Delgado y Plaza (2012) y en Plaza (2008). Asimismo, el balance sobre la proyección, trascendencia e importancia alcanzada por el tratamiento de las áreas de montaña en España, con una relación de los trabajos más señeros, es abordado por Plaza (2008). En el ámbito de la geografía francesa es imprescindIble la cita de Sacareau (2003).

3 Interesantes, desde esta consideración, son las referencias a los trabajos de Collantes (2004a, 2004b), sobre la evolución de la actividad agraria y de la población en las áreas de montaña españolas, y, en relación con los cambios habidos en el paisaje, los de García (1988), Lasanta (1990a, 1990b) o Lasanta, Nadal, Gómez y Serrano (2014). 
los cambios en los municipios de Casla, Prádena, Arcones, Matabuena, Gallegos, Aldealengua de Pedraza, Navafría, Torre Val de San Pedro, Santiuste de Pedraza, Collado Hermoso, Sotosalbos, Santo Domingo de Pirón y Basardilla (Figura 1).

Figura 1. Delimitación del área de estudio dentro del Guadarrama segoviano

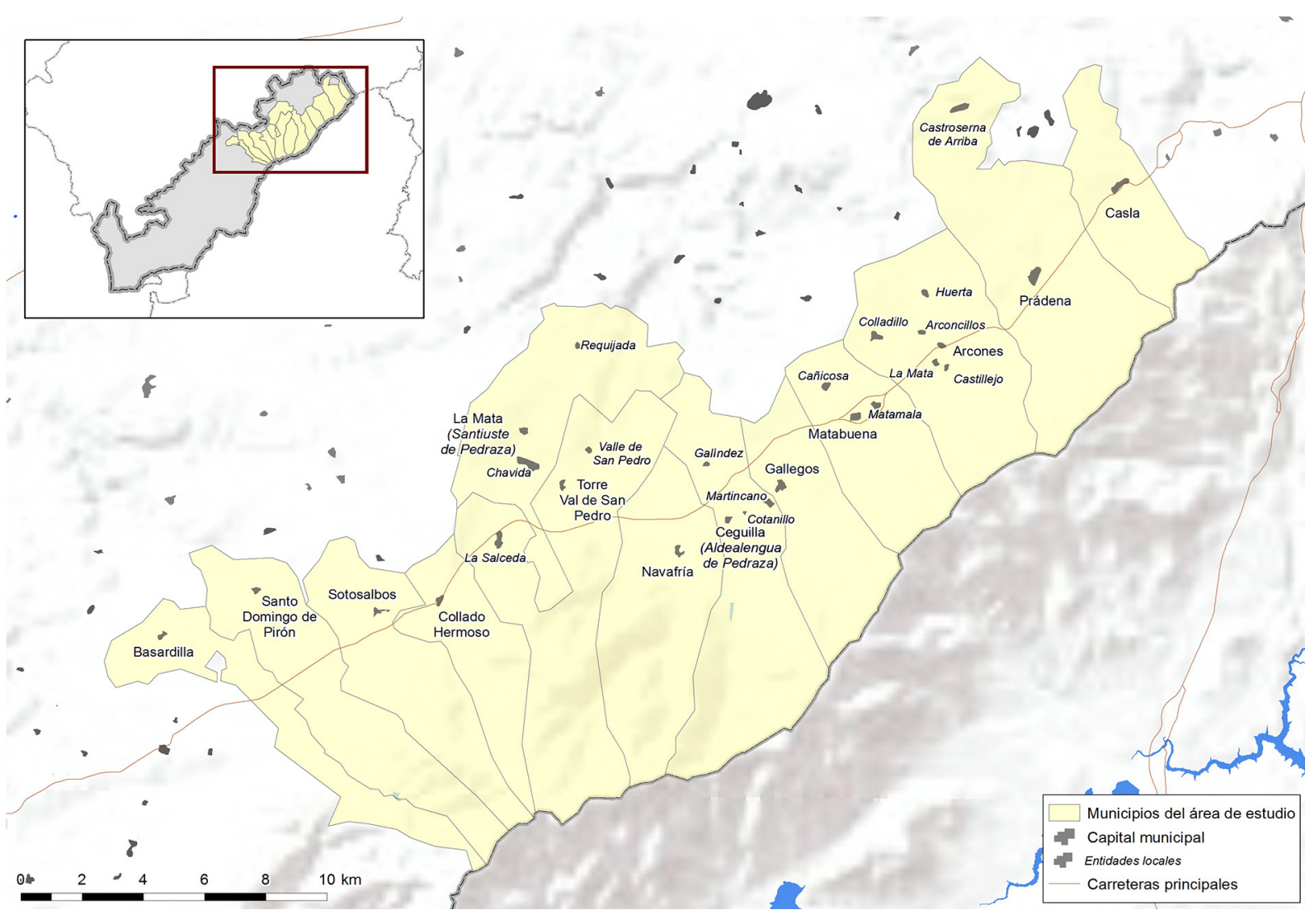

Elaboración propia.

Son todos términos que han articulado, de siempre, sus espacios productivos, compartidos entre una o varias entidades locales diferentes, entre los altos macizos serranos y las peanas de piedemonte sobre las que se asientan. En ello radica su singularidad última dentro del conjunto identificado como el menos transformado -por ser el menos accesible, si cabe- del Guadarrama segoviano (Martínez y Molina, 2015); y que se contrapone, de este modo, con esos otros más fuertemente incididos por la "invasión" foránea -con la intensa producción de espacios urbanizados y de ocio, vinculados a la aglomeración madrileña o al crecimiento periférico de la ciudad de Segovia, que caracterizan al "corredor" El Espinar-Segovia, a La Granja y de manera creciente a los núcleos periurbanos de Tres Casas y Torrecaballeros-. En esencia, es la porción serrana menos evolucionada y en la que mejor se conservan, por ello, las herencias y las huellas de la (des)organización del espacio tradicional. De ahí, finalmente, su interés como ámbito específico a estudiar.

La revisión de las fuentes estadísticas -censos agrarios; censos, nomenclátores y padrones de población-, de la cartografía temática al uso (inventarios forestales) y el recurso a la fotografía aérea, procediendo a establecer la secuencia evolutiva de los cambios territoriales, las herramientas y el método de trabajo a emplear.

\section{LA CRISTALIZACIÓN DE UN MODELO GEOGRÁFICO DE CORTE TRADICIONAL- DEGRADADO}

La larga trayectoria ganadera es el factor dominante de la organización del espacio en los municipios estudiados dentro del aquí denominado Guadarrama segoviano (Tanarro, 1994, 1996). Ahora bien, des- 
de el decenio de 1950 se produce la crisis del sistema tradicional y del modelo territorial en el que este se apoyaba. Sumadas a los concatenados éxodos rural y agrario, la inadecuación de las explotaciones ganaderas, totalmente infradimensionadas, y la falta de dinamismo de las mismas para adaptarse a la nueva realidad económica y social imperante en el país son las razones convencionalmente esgrimidas. Así, la ganadería empieza a entrar en un declive prolongado tanto por los problemas de rentabilidad de las explotaciones familiares (pequeño tamaño, progresivo envejecimiento de los titulares, peso relativo de los ganaderos "a tiempo parcial",...), como, tampoco hay que olvidar, a resultas de los conflictos desatados por la aplicación de las políticas de restricción de los aprovechamientos (licencias de pastos) y de repoblación de los Montes de Utilidad Pública (la calificada por algunos como "euforia pinariega"). Los esquilmos ganaderos reducen, en el trascurso de estos últimos sesenta años, sus efectivos, al tiempo que se conoce una orientación o desorientación, según se mire, de la cabaña pecuaria, que paulatinamente se irá especializando en el bovino, no ajeno a un envilecimiento creciente, por mor de la introducción de razas foráneas de mejores aptitudes para la producción de leche y carne, y que a punto estuvo de hacer desaparecer al vacuno "serrano" o "carpetano" autóctono, en proceso de recuperación actual ${ }^{4}$.

Una degradación del sistema tradicional que se evidencia, a la par, en la inexorable tendencia hacia el abandono y la utilización selectiva del suelo o, lo que es lo mismo, en el declinar de los usos y de la gestión histórica de los espacios productivos: el avance del monte-pinar y la simplificación de los aprovechamientos son sus principales manifestaciones; como también lo son la desaparición o el decaimiento generalizado de los modos de manejo tradicionales: la trashumancia y la trasterminancia estacional. Y es que, unos y otros, definitivamente, no han podido ser mantenidos con fidelidad ante la falta de base social de las colectividades verdaderamente serranas.

\subsection{La dedicación ganadera: evolución y rasgos estructurales}

Las explotaciones en los municipios del área de estudio alcanzaban las 220 en el año 2009 (Tabla 1), habiendo seguido una involución constante, desde 1962, expresada fidedignamente por los datos que decenio a decenio han sido constatados por los correspondientes censos agrarios. Casi 1.100 explotaciones menos en el conjunto de los 13 términos municipales analizados han marcado el signo de los tiempos a lo largo del último medio siglo. Desde los municipios de Prádena (31 explotaciones) y Navafría (30) hasta los de Casla (5) y Collado Hermoso (7), la merma ha sido generalizada para todos. Lejos quedan las cifras de partida, con varios de los términos superando las 100 unidades técnico-económicas de producción agraria (Prádena, 200; Arcones, 180; Navafría, 163; Matabuena, 126; Torre Val de San Pedro, 102) y ninguno por debajo de las 40 (Santo Domingo de Pirón, 42). Así, no es de extrañar que a una distribución menguante del número de explotaciones le acompañe el de unos porcentajes de perdidas de las mismas a todas luces exagerados (Figura 2). En este sentido, y dentro de un mismo panorama de merma de la actividad, han sido establecidos tres umbrales en el decrecimiento de la cuantía de las unidades productivas que se corresponden, además, con una cierta lógica espacial. De este modo, los municipios de Basardilla, Santo Domingo de Pirón y Sotosalbos, los más cercanos a la capital segoviana y a su área de influencia, son los que han registrado, en términos relativos, unas "menores" pérdidas, en torno al 60-75\%. Cierto es que, por esa misma circunstancia señalada, eran los que contaban con los cómputos de partida menos abultados. Les siguen, entre el $75-90 \%$, los restantes a excepción de uno, que son los que concentraban el mayor número de explotaciones en inicio y, por tanto, es en ellos en donde se contabilizan las mayores pérdidas en datos absolutos, llegando a superar el 90\% de merma de las explotaciones censadas. Finalmente, Casla, en el margen oriental, supera holgadamente ese umbral más crítico, pasando, nada más y nada menos, que de 91 unidades de producción en 1962 a 5 en la actualidad.

En paralelo a este descenso constante y generalizado de la cuantía de explotaciones agrarias, la evolución del número de unidades ganaderas en los municipios del área de estudio ha conocido importantes variaciones en el lapso temporal contemplado por los datos censales (Tabla 2). A un aumento moderado

\footnotetext{
4 Desde los años 60 la especialización y el incremento de la cabaña bovina tuvo que ver con la introducción de razas foráneas de mayores rendimientos lecheros -frisonas- o carniceros - charolesas y limousinas- que comenzaron a cruzarse con ejemplares autóctonos de avileña-negra-ibérica, prácticamente abocados a la extinción. Con el cambio de paradigma (del productivismo al posproductivismo) y de orientación de la Política Agraria Común (PAC), que prima e incentiva la extensificación, se ha venido asistiendo al estímulo y efectiva recuperación del vacuno tradicional, mucho mejor adaptado a los caracteres del territorio, y al que aparecen ligadas producciones cárnicas de gran calidad, que están siendo amparadas, además, mediante indicaciones geográficas protegidas (IGP) o marcas de garantía alimentaria.
} 
de UG en el decenio de 1980 le sucede otro más intenso (prácticamente de 3.000 unidades) a lo largo de la década de los años 90. La progresiva especialización en el ganado bovino, tanto en el de orientación lechera, en un primer momento, como en el de aptitud cárnica, con cada vez mayor profusión, hizo que las unidades técnico-económicas de producción que no sucumbían al cese de actividad pudieran incorporarse, de manera más decidida, a la modernización imperante en aquellos momentos dentro del sector (marco productivista $)^{5}$; y que tenía que ver con la mejora sensible de las dimensiones de las explotaciones (dimensión en vacunos) en aras de una mayor rentabilidad de las mismas.

Tabla 1. Evolución del número de explotaciones en los municipios del área de estudio

\begin{tabular}{|lcccccc|}
\hline \multicolumn{1}{c}{ Municipio } & 1962 & 1972 & 1982 & 1989 & 1999 & 2009 \\
Aldealengua de Pedraza & 93 & 65 & 38 & 25 & 28 & 14 \\
Arcones & 180 & 194 & 114 & 39 & 33 & 19 \\
Basardilla & 52 & 68 & 21 & 27 & 22 & 18 \\
Casla & 91 & 71 & 56 & 18 & 12 & 5 \\
Collado Hermoso & 60 & 57 & 15 & 11 & 12 & 7 \\
Gallegos & 77 & 63 & 39 & 28 & 25 & 9 \\
Matabuena & 126 & 79 & 65 & 30 & 37 & 25 \\
Navafría & 163 & 155 & 151 & 138 & 36 & 30 \\
Prádena & 200 & 160 & 113 & 50 & 51 & 31 \\
Santiuste de Pedraza & 83 & 78 & 53 & 43 & 40 & 18 \\
Santo Domingo de Pirón & 42 & 31 & 18 & 21 & 14 & 13 \\
Sotosalbos & 50 & 46 & 22 & 23 & 19 & 15 \\
Torre Val de San Pedro & 102 & 112 & 63 & 71 & 23 & 16 \\
CONJUNTO MUNICIPAL & 1.319 & 1.179 & 768 & 524 & 352 & 220 \\
\hline
\end{tabular}

Fuente: INE: Censo Agrario (varios años).

Figuras 2 y 3. Distribución espacial y evolución del número de explotaciones agrarias y distribución espacial y evolución del número de unidades ganaderas (UG) en los municipios del área de estudio
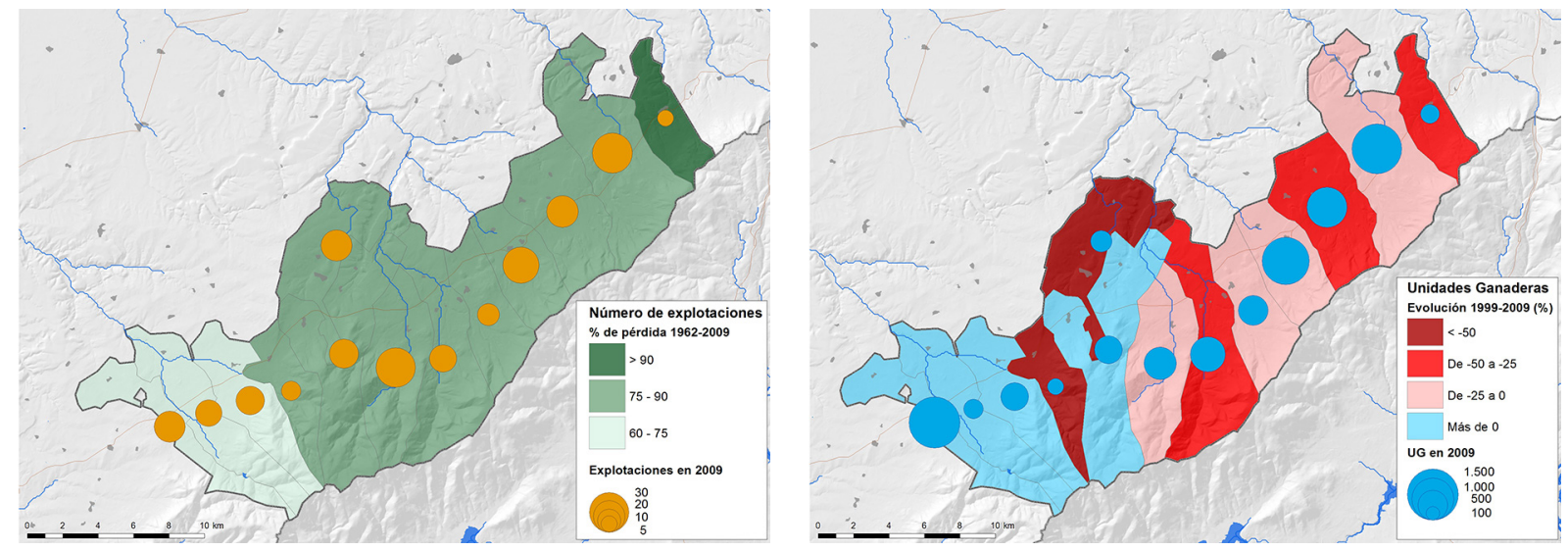

Fuente: INE: Censo Agrario (varios años).

5 Para los hitos temporales contemplados, los datos que hablan de la distribución y cuantía del ganado por especies terminan por explicar la evolución seguida por el número de UG. De este modo, la (des)orientación ganadera, según se prefiera calificar, en los municipios del área de estudio, tiene que ver con una menor impronta total y relativa del ganado ovino, que fue el que tradicionalmente otorgó predicamento y singularidad a este ámbito serrano (pasando de 18.533 cabezas en 1989 a 19.136 en 1999; e iniciándose un irremediable descenso hasta las 10.149 contabilizadas en 2009). Al tiempo, las cabezas de ganado bovino (que son las que más computan para hallar los índices de UG -vacas lecheras: 1; otras vacas: 0,8; bovinos machos de 24 meses y más: 1; bovinos hembras de 24 meses y más: 0,8 ; bovinos de 12 a menos de 24 meses: 0,7; bovinos de menos de 12 meses 0,4- frente al coeficiente de 0,1 consignado para el ovino) han experimentado un incremento considerable entre 1989 y 1999. Y no ya por el vacuno de orientación lechera, que ya en esos momentos conocía una importante recesión (1.564 cabezas en 1989 y 842 en 1999; 563 en 2009), alejada del esplendor del que hizo gala en los decenios de 1960 y 1970, al socaire de los estimulos urbanos demandantes de este tipo de producción por la cercanía al consumidor -y ejemplificada por el significado alcanzado por la Central Lechera Segoviana (CELESE)-, hoy con presencia testimomial en núcleos como Basardilla y, en menor medida, Arcones, Matabuena o Prádena, como por el de aptitud cárnica, la orientación predominante de las explotaciones agrarias de los términos municipales considerados (5.732 cabezas en 1989 y 11.181 en $1999 ; 9.657$ en 2009 ), sobresaliendo, en este sentido, los de Prádena, Basardilla y Matabuena. 
La última década censal ha conocido, sin embargo, una considerable merma en el número total de UG (2.303 unidades menos), manifestada, por los números apuntados al pie, por el tremendo descenso del número de cabezas de ovino (-8.987), de bovino lechero (-279), empero también de vacuno de orientación cárnica (-1.524). Ello, unido a la pérdida durante estos diez años finales de otras 132 explotaciones, es el reflejo más elocuente de la situación de atonía en que se encuenta actualmente la dedicación ganadera en este sector del Guadarrama segoviano. Basardilla, Prádena, Matabuena y Arcones, superando o rozando las 1.000 unidades son los municipios que conservan en mayor medida la actividad ganadera. Una actividad en franco declive a día de hoy en 9 de los 13 términos analizados (Figura 3). Y da igual que estos sean los de Arcones, Matabuena o Prádena, por su significado, que los de Aldealengua de Pedraza, Casla, Navafría o incluso Gallegos; encontrando los casos más extremos, con descensos de más del 50\% de unidades ganaderas, en Collado Hermoso o Santiuste de Pedraza. Nuevamente son los municipios más cercanos al área de influencia de la capital (Santo Domingo de Pirón, Sotosalbos y, sobre todo, Basardilla -1.472 UG, con un incremento de 403 entre 1999 y 2009-), además de Torre Val de San Pedro, los que logran aumentar la cuantía de unidades ganaderas; repartidas, eso sí, en un número cada vez más reducido de explotaciones, que, como es lógico pensar, mejoran de esta forma su dimensión y rentabilidad.

Tabla 2. Evolución del número de unidades ganaderas (UG) en los municipios del área de estudio

\begin{tabular}{|lcccc|}
\hline \multicolumn{1}{c}{ Municipio } & 1982 & 1989 & 1999 & 2009 \\
Aldealengua de Pedraza & 596 & 502 & 984 & 690,90 \\
Arcones & 1.115 & 1.002 & 1.266 & 907,63 \\
Basardilla & 570 & 732 & 1.069 & $1.471,96$ \\
Casla & 203 & 196 & 355 & 188,10 \\
Collado Hermoso & 184 & 207 & 304 & 147,30 \\
Gallegos & 546 & 391 & 488 & 483,40 \\
Matabuena & 744 & 986 & 1.603 & $1.247,06$ \\
Navafría & 569 & 450 & 771 & 586,00 \\
Prádena & 1.108 & 1.226 & 1.463 & $1.396,90$ \\
Santiuste de Pedraza & 382 & 645 & 1.473 & 246,11 \\
Santo Domingo de Pirón & 475 & 398 & 172 & 208,30 \\
Sotosalbos & 413 & 632 & 378 & 426,78 \\
Torre Val de San Pedro & 428 & 410 & 407 & 431,10 \\
CONJUNTO MUNICIPAL & 7.333 & 7.777 & 10.733 & $8.430,54$ \\
\hline
\end{tabular}

Fuente: INE: Censo Agrario (varios años).

Con todo, dentro del espacio de estudio, y en un mismo contexto de crisis de la actividad ganadera secular, puede ser establecida una diferenciación municipal, por agregación de las explotaciones radicadas en cada uno de los términos, en función de los parámetros más significativos que caracterizan a la actividad pecuaria en la actualidad. Es así como, más allá de las cifras que hacen mención al cómputo individualizado de explotaciones y de UG, las desiguales improntas ganaderas a escala municipal cobran carta de entidad al poner en relación ambas variables con el contingente poblacional de cada uno de los municipios de análisis. Así, la densidad ganadera vendría dada por el cociente entre el censo de ganados, convertido a unidades ganaderas, y el número de habitantes (Figura 4). Si el promedio del conjunto es de 3,2 unidades ganaderas por habitante, los valores oscilan entre Basardilla $(8,8)$, Aldealengua de Pedraza $(6,9)$, Gallegos $(4,9)$ y Matabuena $(4,9)$, por una parte, y Collado Hermoso $(0,9)$, Casla $(1,1)$, Navafría $(1,5)$, Santiuste de Pedraza $(2,1)$, Torre Val de San Pedro $(2,2)$ y Prádena $(2,4)$, por la contraria, quedando el resto en valores próximos a la media. No ocurre exactamente lo mismo con la dedicación ganadera, calculada a partir del número de explotaciones por cada cien empadronados (Figura 5). La media es de 8,2, siendo ocho los municipios que la superan, con Santo Domingo de Pirón (20 explotaciones por cada 100 habitantes), Santiuste de Pedraza (15,5), Aldealengua de Pedraza (14), Sotosalbos (11,5) y Basardilla $(10,8)$, superando la decena, y Casla (3), Collado Hermoso $(4,2)$ y Prádena $(5,3)$, en valores inferiores a la mitad de los anteriores.

Los matices encontrados entre ambos indicadores tienen que ver, como no podía ser de otra manera, con las diferencias existentes en la dimensión de las explotaciones, aspecto muy a tener en cuenta, pues de ello se desprende el verdadero grado de dedicación ganadera, es decir, la intensidad con la que se realizan los esquilmos pecuarios en cada una de las unidades de producción censadas (Figura 6). Es Basardilla, el municipio de mayor densidad ganadera, el que concentra las explotaciones de mayor dimensión $(81,8$ 
UG por explotación), situándose a mucha distancia otros que igualmente superan el promedio del conjunto (38,3), como Gallegos (53,7), Matabuena (49,9), Aldealengua de Pedraza $(49,3)$, Arcones $(47,8)$ y Prádena $(45,1)$. Son los que, se presume, concentran las explotaciones que pudieran considerarse como aceptables (en torno al medio centenar de vacas, en una explotación tipo orientada al vacuno de carne). Destacan también Basardilla (a sumar 350 cabezas de vacuno lechero) y Arcones (125) con explotaciones orientadas al bovino de leche (e incluso granjas porcinas -210 y 307 cabezas de cerdos, respectivamente-); o Matabuena (2.020 ovejas) y Prádena (2.017), que prosiguen con una cierta especialización ovina (y más reciente cunícola en el segundo de ellos -700 conejos). De ello se deriva, en última instancia, el dinamismo económico que acompaña a las variaciones en la dimensión de las explotaciones y que aparece claramente ligado a la especialización y modernización de las mismas. Así, la distribución de la producción estándar total (PET) por unidad de producción se corresponde con los municipios que albergan las explotaciones más boyantes, mientras que las PET menos cuantiosas aparecen vinculadas a las explotaciones ubicadas en los municipios ganaderos menos evolucionados o de una economía más diversificada y en proceso de transformación funcional ${ }^{6}$ (Figura 7). Sobresalen, en este sentido, las explotaciones de Basardilla (87.619,9 euros), Arcones $(53.651,3)$, Prádena $(49.539,6)$, Gallegos $(47.468,4)$ y Matabuena $(41.673,5)$, quedando como explotaciones marginales las de Santiuste de Pedraza (12.498,9), Navafría (14.541,5), Santo Domingo de Pirón $(15.369,4)$, Collado Hermoso $(20.880,9)$, Sotosalbos $(22.905,7)$ y Torre Val de San Pedro (27.916).

Figuras 4, 5, 6 y 7. Densidad ganadera, dedicación ganadera, dimensión ganadera de las explotaciones agrarias y producción estándar total (PET) por explotación en los municipios del área de estudio
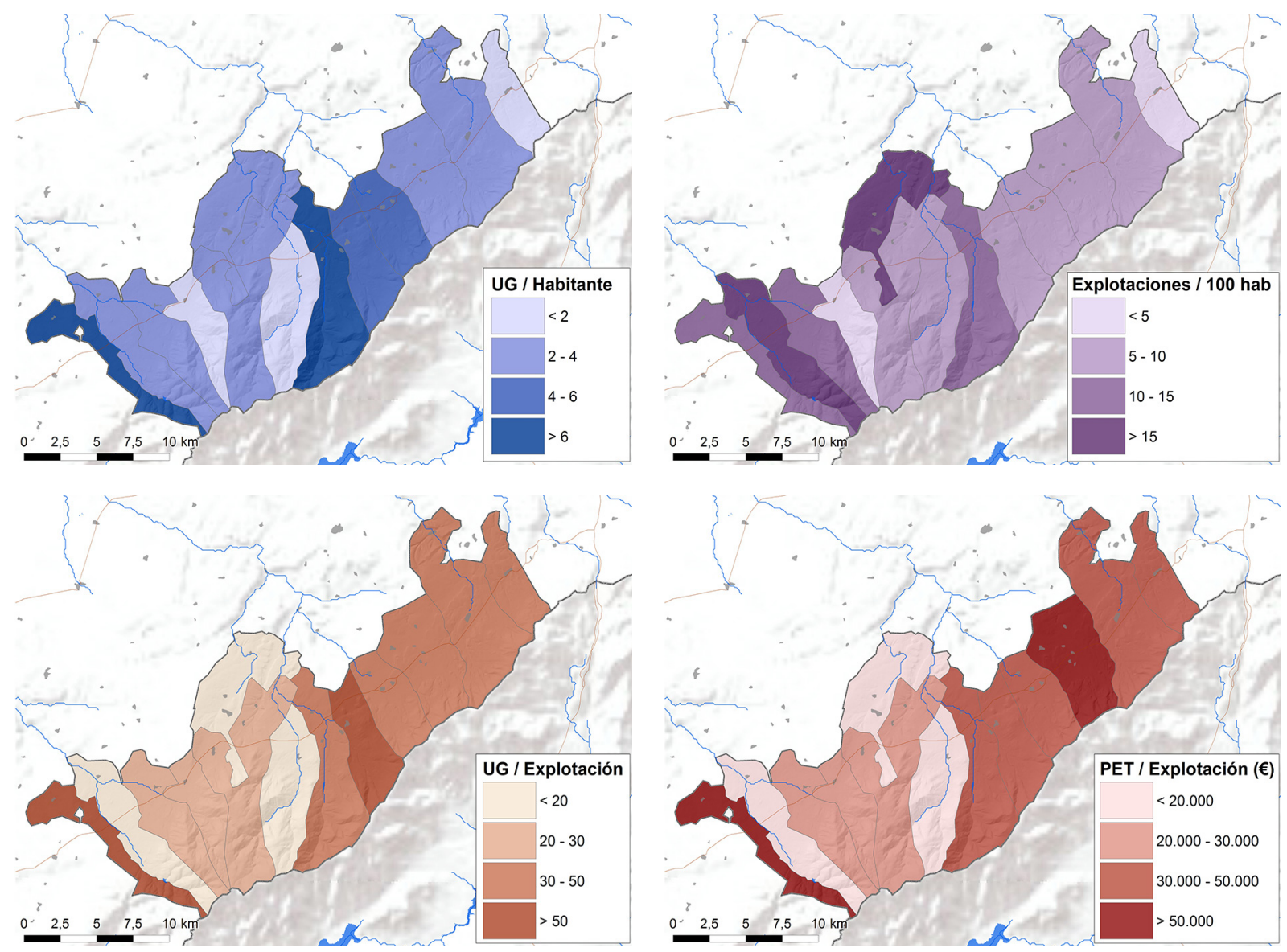

Fuente: INE: Censo Agrario, 2009 y Padrón Municipal de Habitantes, 2009.

6 Desde el Censo Agrario de 1999, la producción estándar (PE) se calcula multiplicando la producción por unidad de ganado por el precio de salida de la explotación sin incluir el IVA, los impuestos sobre los productos y los pagos directos. La producción estándar total (PET) es la suma de las producciones estándar de todas las actividades de la explotación. 
Municipios, muchos de estos últimos mencionados, en los que más se dejan sentir los síntomas de una gestión de las explotaciones vinculada al envejecimiento demográfico. Términos municipales, todos en su conjunto, en los que en mayor o menor medida la ocupación agraria es compaginada con otro tipo de actividad (según la explotación estadística de Datos de Afiliación de Trabajadores al Sistema de la Seguridad Social, para diciembre de 2013, únicamente el 14,5\% de los empleos registrados en los trece municipios correspondían con el sector agrario sensu stricto). Y es así, por medio de la "actividad compartida"7, de las rentas complementarias y, por qué no decirlo, de la "subvención", como, explotaciones excepcionales al margen, pervive o, mejor cabría decir, "sobrevive" la dedicación ganadera en la actualidad.

\subsection{El abandono y la degradación del uso tradicional del suelo}

Si en el modelo tradicional la explotación de los semovientes alcanzaba una gran complejidad siguiendo unas pautas depuradas por el tiempo en el manejo de los animales y en una utilización equilibrada de la variedad de recursos que "escalonadamente" presentaba el espacio, desde al menos el decenio de 1960 la degradación coetánea al declinar de las prácticas ganaderas se ha hecho patente en una evidente simplificación de dicho modelo, comenzando por reducir el número de especies aprovechadas prácticamente a una, el bovino (sin dejar de ser del todo desdeñables las cifras que todavía arrojan los hatos de ovejas), y a homogeneizar los usos del suelo, que en manos individuales se desprenden, además, de las reglas y normas otrora dadas por las comunidades serranas para su velado cuidado.

En este estado de cosas, la explotación ganadera se orienta decididamente hacia la producción de vacuno de carne, pues la puesta en el mercado de los terneros es el fin último de una parte sustancial de las unidades técnico-econónicas contempladas en el censo agrario. Para lograr tal objetivo, las explotaciones cuentan, en esencia, con dos tipos de medios: los que se pueden obtener de las fincas individuales -los "campos cercados"-, ya sean propias o arrendadas, y los que proporcionan los pastizales de diente distribuidos por los diferentes Montes de Utilidad Pública existentes en los municipios objeto de estudio. Los ganados, en régimen semiextensivo, por mor de los aditamentos de la "subvención" (primas a la extensificación), aparentarían seguir, a priori, el mismo ciclo histórico de desplazamientos estacionales entre el "alto de la sierra" -los puertos y majadas estivales- y las cuadras y establos de la larga invernada en el piedemonte; pero sin la presencia, en todo caso, de muchos de aquellos espacios colectivos de raigambre tradicional: "dehesas", "ejidos", "alijares"9; sin sus "aperturas", sin las fechas de cierres, progresivamente decantados en una tesela banalizada de usos del suelo.

Tabla 3. Evolución de la superficie agrícola utilizada (SAU en ha) en los municipios del área de estudio

\begin{tabular}{|lcccccc|}
\hline \multicolumn{1}{c}{ Municipio } & \multicolumn{2}{c}{1989} & \multicolumn{2}{c}{1999} & \multicolumn{2}{c|}{2009} \\
Aldealengua de Pedraza & Pastos & Labrantíos & Pastos & Labrantíos & Pastos & Labrantíos \\
Arcones & 940 & 7 & 1.064 & 0 & 1.157 & 16 \\
Basardilla & 1.242 & 178 & 1.440 & 62 & 1.074 & 296 \\
Casla & 1.496 & 0 & 674 & 23 & 1.037 & 5 \\
Collado Hermoso & 472 & 16 & 683 & 0 & 483 & 0 \\
Gallegos & 150 & 1 & 53 & 0 & 541 & 110 \\
Matabuena & 894 & 8 & 1.016 & 0 & 450 & 5 \\
Navafría & 589 & 9 & 1.068 & 0 & 1.071 & 14 \\
Prádena & 843 & 101 & 5.276 & 0 & 1.209 & 4 \\
Santiuste de Pedraza & 1.826 & 235 & 2.622 & 163 & 1.620 & 221 \\
Santo Domingo de Pirón & 2.697 & 100 & 1.319 & 407 & 696 & 80 \\
Sotosalbos & 617 & 0 & 922 & 0 & 894 & 15 \\
Torre Val de San Pedro & 1.978 & 0 & 241 & 0 & 1.162 & 0 \\
CONJUNTO MUNICIPAL & 2.732 & 91 & 752 & 4 & 1.375 & 205 \\
\hline
\end{tabular}

Fuente: INE: Censo Agrario (varios años).

7 Concepto mucho más amplio que el de la simple "pluriactividad", que hace referencia, concretamente, al campesino que comparte su explotación agraria con otra actividad económicamente remunerada. Dejando fuera de la definición, de ese modo, al importante segmento de población jubilada al frente de explotación (Ortega, 1989, p. 121).

8 En realidad, las ayudas directas de la PAC en apoyo compensatorio al declive de las rentas agrarias en Europa (las correspondientes al "primer pilar", frente a las del "segundo pilar" o medidas de desarrollo rural) llegan a todos los ganaderos titulares de explotación, con independencia del grado de "profesionalización" y si la actividad es principal o secundaria (es más, para el nuevo periodo de programación 2014-2020 se contempla que un agricultor "activo" es quien obtenga, al menos, un $20 \%$ de los ingresos de la actividad y el resto de subvenciones). Por consiguiente, no dejan de cobrar importancia tanto los jubilados de la actividad, que ven compensadas, de esta forma, sus contenidas prestaciones contributivas, como los ocupados en otros sectores, que tienen en la explotación agraria -vía subvención-su fuente de complemento de rentas. Con todo, la disponibilidad de pagos compensatorios también ha sido determinante para el mantenimiento y consolidación de una ganadería con carácter empresarial y competitivo. Unas ayudas de la PAC que aparecen vinculadas, fundamentalmente, con los "derechos de pago único", primando la extensificación y a las vacas nodrizas.

9 Sobre la organización histórica de los espacios pastables del Guadarrama ha tratado recientemente Vías (2014). 
Con un tamaño medio por explotación de 38,3 unidades ganaderas, la degradación de la actividad, más allá de la simplificación alcanzada por la fisonomía y funcionalidad de los espacios productivos, toma cuerpo al considerar, igualmente, la vigorosidad con la que se realiza el aprovechamiento de los homogeneizados usos del suelo. Si viene a ser una máxima el dimensionar las explotaciones "puras" (las más dinámicas) a partir de las posibilidades de alimentación del ganado en el periodo de estabulación invernal (que se puede alargar varios meses), aquilatando la cabaña a la entidad de los recursos almacenados propios (también los derivados de las parcas producciones agrícolas de clara orientación pecuaria), aún a costa de forzar siempre esa ecuación por el lado del número de animales mantenidos, sin buscar una excesiva dependencia de los insumos externos que condicionarían enormemente la rentabilidad, y si el peso que adquieren las explotaciones "mixtas" (las enmarcadas en el amplio abanico de titulares con "actividad compartida") no se encamina, precisamente, hacia la consolidación de unidades técnico-económicas de mayores dimensiones, no es de extrañar que la relación entablada entre ganaderías y superficie agrícola utilizada (SAU) en los municipios del Guadarrama segoviano analizados, lejos de mantenerse, lo que según los datos aconteciera durante el decenio de 1990, manifieste ya, a lo largo de los 2000, un considerable descenso, que hace que sean 4.363 las hectáreas abandonadas de "pastos"10 (Tabla 3); en un lapso, como se recordará, en el que se produjo el cese de 132 explotaciones, y en el que el declinar de la actividad se manifiesta, de modo similar, en una merma del cómputo de unidades ganaderas de -2.302 .

Por términos, en el trascurso de los últimos veinte años censados, son los de Aldealengua de Pedraza (217 ha), Casla (11 ha), Collado Hermoso (391 ha), Matabuena (482 ha), Navafría (366 ha) y Santo Domingo de Pirón (277 ha) los que han incrementado la utilización de las superficies pratenses de las explotaciones agrarias -a expensas de antiguas tierras de labor-. Por el contrario, el abandono generalizado se debe a lo ocurrido en los casos de Arcones (-168 ha), Basardilla (-459), Gallegos (-444 ha), Prádena (-206), Santiuste de Pedraza (-2.001), Sotosalbos (-816) y Torre Val de San Pedro (-1.357). Más que al abandono de los "prados o praderas permanentes", es decir, de los "campos cercados", que también, o de una recurrente estabulación del ganado que se aviene mal con las directrices emanadas de la PAC (una extensificación que no en raras ocasiones, por otra parte, es desvirtuada en sentido inverso, como el deambular "descontrolado" de ganados por eriales y abertales manifiesta), el avance del matorral, de las sabinas albares, las repoblaciones de pinar y, en suma, el constreñimiento y aprovechamiento selectivo de las "superficies utilizadas para pastos" en los Montes de Utilidad Pública parecen ser las explicaciones más plausibles. Y es esta misma realidad, la del abandono y degradación del uso tradicional de los espacios productivos, la que termina por ser fehacientemente expresada por otro tipo de fuente de información: la que viene suministrada por los inventarios forestales, cuyas proyecciónes cartográficas no dejan lugar a duda alguna (Figuras 8 y 9).

Figuras 8 y 9. Usos del suelo inventariados en los municipios del área de estudio
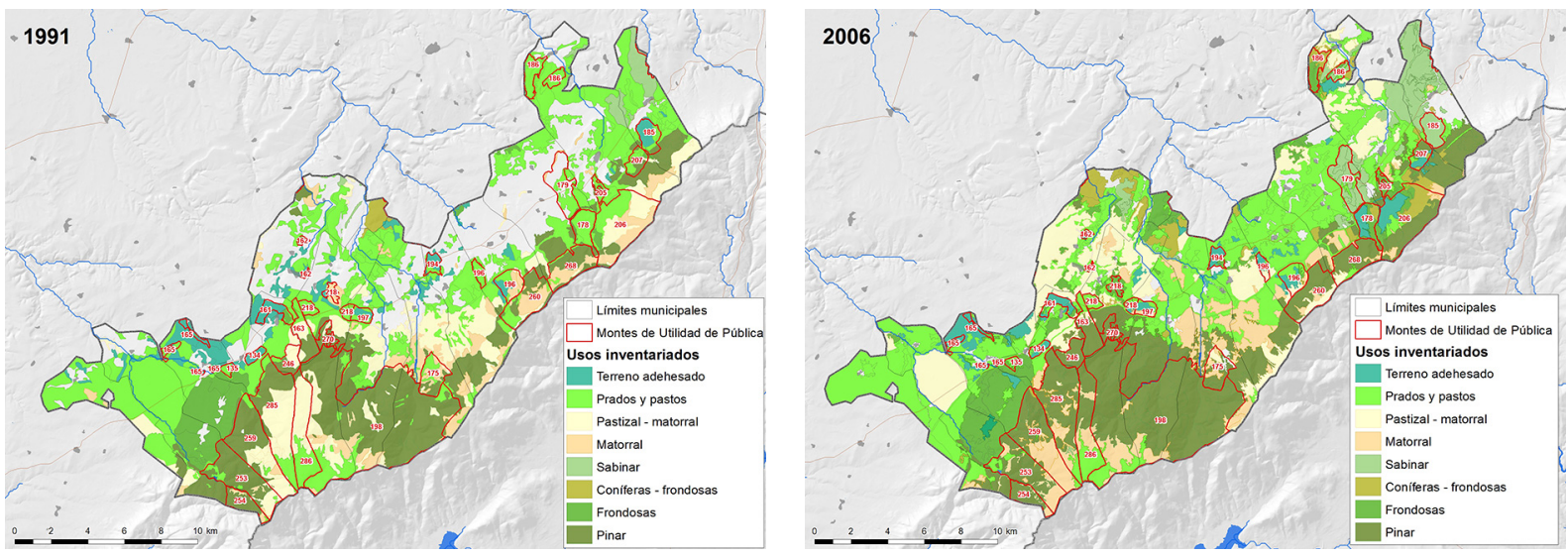

Fuente: MAGRAMA: Segundo Inventario Forestal Nacional y MAGRAMA: Tercer Inventario Forestal Nacional. Elaboración propia.

10 Según la definición recogida en el Censo agrario, se entiende por Superficie Agrícola Utilizada (SAU): "el conjunto de la superficie de tierras labradas y tierras para pastos permanentes". Son tierras para pastos permanentes aquellas "no incluidas en la rotación de cultivos, dedicadas de forma permanente a la producción de hierba". Distinguiéndose entre prados o praderas permanentes: "tierras dedicadas permanentemente a la producción de hierba"; y otras superficies utilizadas para pastos: "terrenos no comprendidos en el apartado anterior que se han utilizado como pasto para el ganado". 
Unos usos del suelo con dedicación ganadera repartidos en una conjunción básica compuesta por los dominantes prados y praderas naturales y los pastos de diente, considerados todavía como estratégicos y la verdadera piedra angular de la conservación secular de la actividad. Suelos, degradados en sus usos, simplificados en sus formas; aprovechamientos del suelo entendidos como superficies agrarias utilizadas en un continuado y progresivo declinar, por lo comentado a la luz de las estadísticas y lo reflejado en los mapas e imágenes (Figuras 10 a 17). El de los terrazgos cultivados, sin particular predicamento por los predios de la comarca, en una pratificación constante a lo largo, por lo menos, de los últimos cincuenta años. El de los prados y praderas, expandidos a costa de los anteriores, y a merced, hoy, del irremediable avance de matorrales (tomillares, cantuesales, jarales, zarzales, rosales y, sobre todo, piornales) y enebrales, como síntoma y significado del declive de la dedicación. Y el de los montes, algunos aún conservando restos de antiguas "dehesas", más propiamente terrenos adehesados que dehesas en la actualidad, y los de mayor extensión albergando los puertos y majadas de las "cimeras" serranas: olvidados los más inaccesibles, al socaire de la matorralización creciente (piornales, enebrales rastreros, brezales,...) y las omnipresentes repoblaciones de pinar, que vienen marcando desde hace décadas los usos hegemónicos de la "alta sierra"; sobrecargados y sin excesiva reglamentación los que a duras penas conservan su función como "agostaderos". Declive y degradación, abandono y simplificación. Las dos caras de una misma moneda. La de unas prácticas ganaderas actuales que, lejos de representar la continuidad de la tradición, agonizante en un maltrecho pervivir, ven comprometida su "supervivencia" futura al mantenimiento de la complementariedad de la "actividad compartida" y a los jugosos suplementos de la "subvención".

Figuras 10, 11, 12 y 13. Evolución del espacio serrano en el sector SO del área de estudio
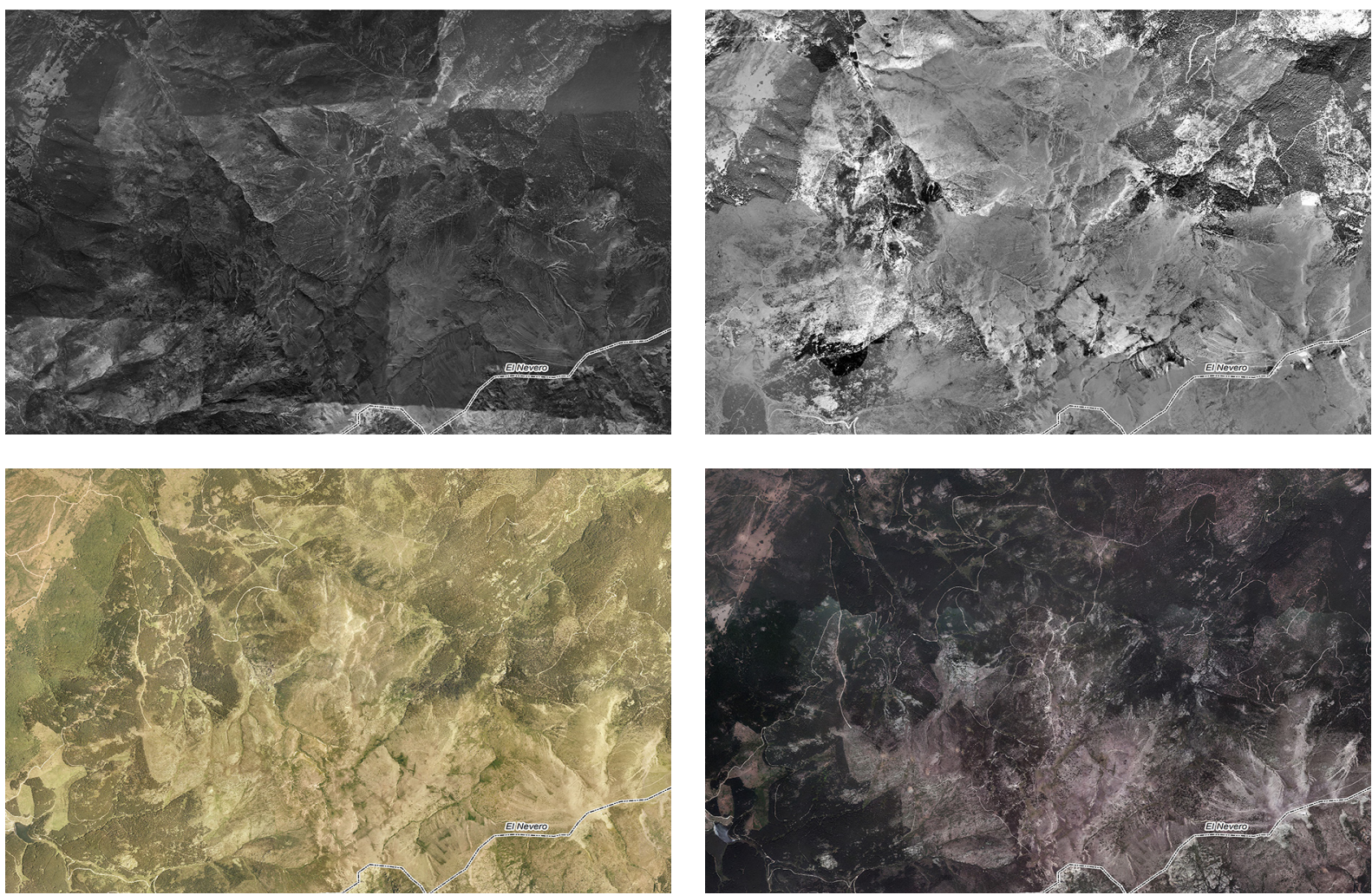

El paisaje de las laderas y el "alto de la sierra" evidencia en los años 50 las huellas del modelo tradicional (arriba a la izquierda): "matas"de robles (parcialmente la del Pirón), "rasos" y "alijares", pinares históricos (el de Navafría, a poniente) y "agostaderos" de alta montaña (macizo de El Nevero). La crisis y consecuente simplificación del sistema motivó el progresivo abandono y la transformación de muchos de estos componentes. Las roturaciones ("rasos") y "alijares" van siendo cubiertos por las florestas arbóreas y el matorral (arriba a la derecha), mientras que ya se perciben los efectos de una más que decidida expansión del pinar, que va cubriendo la mayor parte de las laderas serranas (englobadas en varios MUP). Por encima del dosel pinariego, el ambiente cumbreño continúa, también más recientemente (abajo a derecha e izquierda), soportando a los pastizales de los puertos y majadas más apetecidos del área de estudio (los comprendidos entre los puertos de Malagosto y de Navafría), que en detalle ven, sin embargo, constreñir los herbazales de muchas de sus camperas, las más inaccesibles e inhóspitas, a merced de piornales y jabinares. Como ocurre un poco más abajo, en donde al avance del pinar parece antecederle el de una matorralización creciente, que testimoniaría la sucesión de estadios vegetales. Síntomas a las claras del declive y la degradación actual de la dedicación ganadera y de sus imágenes territoriales más representativas.

Fuente: CIT e ITACyL: Archivo de ortofotos históricas (Vuelo Americano 1956-1957 y Vuelo IRYDA 1977-1983), Ortofoto PNOA 2004 de Castilla y León y Ortofoto PNOA 2014 de Castilla y León. 
Figuras 14, 15, 16 y 17. Evolución del espacio serrano en el entorno de Prádena
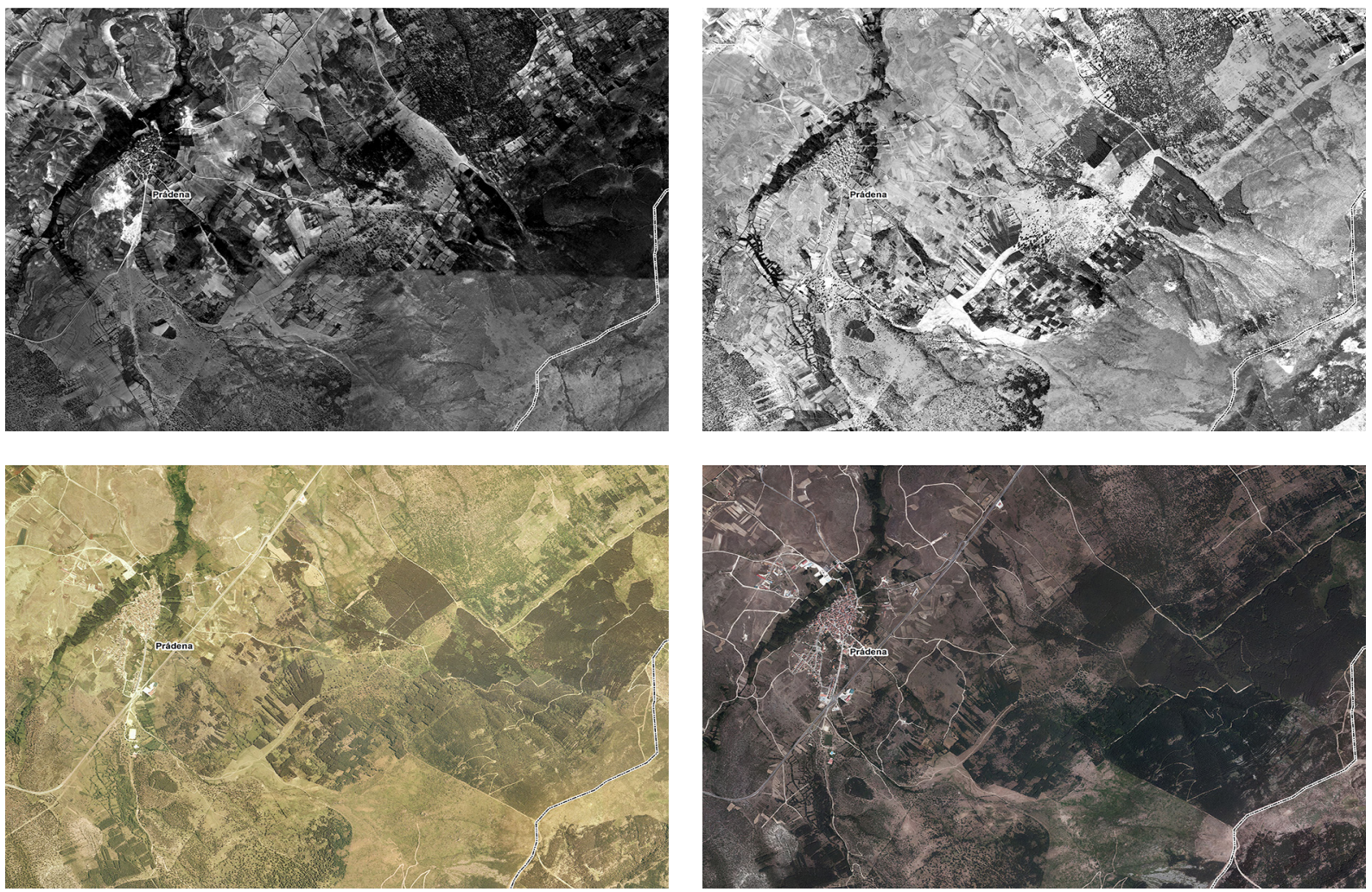

En los años 50, el mantenimiento de la población (1.012 habitantes censados en Prádena al comienzo de esa década) obligaba a un aprovechamiento intenso del terrazgo cultivado, cuyo principal fin era la alimentación humana y del ganado en el marco de un sistema agrario de subsistencia. De ahí la trascendencia que (arriba a la izquierda) adquieren las tierras de labor, ocupando importantes extensiones, tanto en el piedemonte como en la parte más baja de las laderas, y caracterizándose por una excesiva parcelación. Por el contrario, las masas forestales se veían reducidas, por mor de la dilatada ocupación y utilización histórica del territorio que había traído consigo la deforestación, con la quema y roturación ("rasos") de la mayor parte de la cobertera arbórea ("dehesas" y "matas de robles"). Así, la porción más sustancial del espacio no cultivado estaba ocupada por prados, generalmente "cercados" y arbolados, que se concentraban en los lugares más aptos del piedemonte y al pie de la "sierra", además de los pastizales de diente ganados a costa del monte y entreverados al matorral en las laderas altas y "cimeras". Al columbrar el decenio de 1980 (arriba a la derecha), el abandono consecuente al éxodo masivo de los años 60 y 70 (Prádena contaba con 518 residentes en 1981; cifra que prácticamente mantiene hasta la actualidad) se manifiesta claramente en la reducción de los terrenos agrícolas (localizados, los que se mantienen, en torno al núcleo). Los antiguos campos cultivados se convierten, pues, en eriales y pastizales que son aprovechados de forma extensiva por la ganadería, fundamentalmente, aún en ese momento, lanar (con la trashumancia de radio largo desaparecida por completo desde los años 60, el pasado ovino se deja entrever también en la secuencia fotográfica con el nítido trazado de la "Cañada de la Vera de la Sierra"). Con todo, el avance de la vegetación natural ya es un hecho perfectamente constatable, así como las huellas de los incipientes pinares de repoblación. En el trascurso de los últimos diez años (abajo a izquieda y derecha), la degradación de los usos tradicionales, consustanciales al declinar de la dedicación pastoril, hace que esos mismos signos del declive de la tradición constituyan, ya sin remisión, las trazas más expresivas de la (des)organización del paisaje: los "campos cercados" son dejados a merced de la colonización vegetal, que al detalle mostraría igualmente los muros de piedra desparramados sobre el suelo; al tiempo prosigue la enorme expansión de los enebrales, que dominan por doquier sobre las superficies aplanadas de la "rampa"; y, finalmente,

las repoblaciones de pinar, algunas tan recientes como lo evidencian las propias terrazas preparadas para la plantación.

Fuente: CIT e ITACyL: Archivo de ortofotos históricas (Vuelo Americano 1956-1957 y Vuelo IRYDA 1977-1983), Ortofoto PNOA 2004 de Castilla y León y Ortofoto PNOA 2014 de Castilla y León.

\section{DE LA DESVITALIZACIÓN DEMOGRÁFICA A LA DISOLUCIÓN SOCIAL}

A partir de 1950, la crisis del sistema agrario tradicional, que ha desembocado paulatinamente en una organización degradada del modelo ganadero, como se acaba de apuntar, tuvo como correlato la del propio armazón territorial en el que se apoyaba. Se hicieron evidentes de esa manera, pues, las limitaciones de la estructura productiva de raigambre histórica para manterner en condiciones de vida dignas a unas comunidades serranas mucho más abundantes que las actuales. La emigración, como consecuencia también de los cambios socioeconómicos conocidos por el país desde ese mismo momento (desarrollismo y concentración urbana), ha venido marcando las claves de una constante involución de la población residente en los términos municipales analizados, que solamente en el último decenio han visto aumentar 
sus vecindarios en conjunto, a resultas de la tenue dinámica demográfica expansiva experimentada por algunos de ellos, los más diversificados, en una primera aproximación, al ser los que mayor sintonía tienen, si cabe, con los influjos irradiados desde allende la "Sierra", tendentes a una integración espacial de los mismos en la órbita de la dominancia urbana, que, como aconteciera décadas atrás en las comarcas colindantes, comienzan a penetrar en este ámbito del Guadarrama segoviano (que es el menos "colonizado" desde la perspectiva de las demandas de ocio y "esparcimiento" de los habitantes de la ciudad). Es así como la (des)organización del territorio serrano se manifiesta, como otra dimensión a añadir al modelo geográfico de corte tradicional-degradado gestado desde mediados de la centuria anterior, en un prolongado proceso de despoblación -y de despoblamiento-, atestiguado sin ningún género de duda por las sensibles mermas registradas censo a censo en las densidades de ocupación del espacio o las perceptibles modificaciones habidas en el tamaño y número de asentamientos, y en un absoluto agotamiento social, como el excesivo grado de envejecimiento y el lábil movimiento natural de los menguados habitantes en la actualidad terminan por demostrar.

\subsection{La pérdida poblacional como una constante en la evolución demográfica}

El descenso del número de habitantes es un hecho constatable y extensible a todo el siglo XX. Como en otros espacios montañosos, las pérdidas demográficas que afectaron a la práctica totalidad de las áreas rurales españolas a partir de 1950 tienen su antecedente en la primera mitad de esa centuria (952 residentes menos); con los municipios de Arcones y de Santo Domingo de Pirón como únicas salvedades. Sin embargo, es desde ese decenio central y hasta 2001, sin remisión, cuando la evolución de la población registrada en el conjunto territorial toma los tintes de lo que sin exagerar podría denominarse como una sangría poblacional (Tabla 4 y Figuras 18 a 21).

Tabla 4. Evolución de la población censada en los municipios del área de estudio

\begin{tabular}{|lcccccccc|}
\hline \multicolumn{1}{c}{ Municipio } & 1900 & 1950 & 1960 & 1970 & 1981 & 1991 & 2001 & 2011 \\
Aldealengua de Pedraza & 685 & 387 & 422 & 235 & 101 & 111 & 93 & 100 \\
Arcones & 903 & 1.119 & 936 & 497 & 355 & 288 & 228 & 249 \\
Basardilla & 296 & 266 & 251 & 153 & 96 & 117 & 106 & 167 \\
Casla & 569 & 388 & 359 & 213 & 127 & 150 & 151 & 162 \\
Collado Hermoso & 346 & 342 & 292 & 120 & 125 & 122 & 154 & 160 \\
Gallegos & 622 & 420 & 402 & 213 & 144 & 100 & 97 & 97 \\
Matabuena & 658 & 638 & 640 & 403 & 209 & 225 & 243 & 254 \\
Navafría & 756 & 736 & 815 & 509 & 427 & 422 & 364 & 374 \\
Prádena & 1.382 & 1.296 & 1.112 & 732 & 599 & 541 & 548 & 597 \\
Santiuste de Pedraza & 532 & 443 & 424 & 275 & 146 & 126 & 95 & 105 \\
Santo Domingo de Pirón & 172 & 179 & 171 & 110 & 74 & 51 & 66 & 64 \\
Sotosalbos & 416 & 315 & 307 & 175 & 99 & 98 & 131 & 131 \\
Torre Val de San Pedro & 926 & 782 & 754 & 370 & 203 & 197 & 189 & 194 \\
CONJUNTO MUNICIPAL & 8.263 & 7.311 & 6.885 & 4.005 & 2.705 & 2.548 & 2.465 & 2.654 \\
\hline
\end{tabular}

Fuente: INE: Censo de Población y Viviendas (varios años).

Entre 1950 y 2001 todos los municipios sin excepción ven mermar estrepitosamente su población, con unas tasas medias anuales de crecimiento acumulado -mejor sería decir decrecimiento-inferiores al $-1 \%$ (Aldealengua de Pedraza, -2,8\%; Arcones, -3,1\%; Basardilla, -1,8\%; Casla, -1,8\%; Collado Hermoso, -1,6\%; Gallegos, -2,8\%; Matabuena, -1,9\%; Navafría, -1,4\%; Prádena, -1,7\%; Santiuste de Pedraza, -3\%; Santo Domingo de Pirón, -1,9\%; Sotosalbos, -1,7\%; y Torre Val de San Pedro, -2,8\%). Ante estas cifras, puede afirmarse, sin equívocos, que más que por la dinámica natural, por otra parte positiva aún hasta avanzados los años 70, cuando ya se dejan sentir los efectos de la salida poblacional en la caída de la natalidad, la constante emigratoria se erige en factor explicativo de la regresiva evolución demográfica conocida por el espacio serrano. Una emigración que tiene en las décadas de los 60 (2.880 habitantes menos) y de los 70 (otros 1.300 a añadir a las pérdidas) su momento álgido, con la desfavorable antesala computada a lo largo del decenio de 1950 (-426 censados), y los epigonos de los 80 (-157) y 90 (-83). En suma, 4.846 residentes menos en el trascurso de medio siglo, 5.798 si la cuenta se amplia al siglo entero.

El primer balance intercensal de la nueva centuria ha traído, empero, un cambio en la prolongada tendencia a la baja de las contabilidades poblacionales. Así, solamente el municipio de Santo Domingo de Pirón continúa mostrando una tasa media anual de crecimiento acumulado negativa, aunque más 
moderada (-0,3\%), y otros dos, los de Gallegos y Sotosalbos, reflejan un crecimiento cero. Por contra, Aldealengua de Pedraza (0,7\%), Arcones (0,9\%), Basardilla (4,7\%), Casla (0,7\%), Collado Hermoso $(0,4 \%)$, Matabuena ( $0,4 \%)$, Navafría ( $0,3 \%)$, Prádena (0,9\%), Santiuste de Pedraza ( $1 \%)$ y Torre Val de San Pedro $(0,3 \%)$, anotan los porcentajes positivos. 189 habitantes censados más como expresión, quizás, de una ligera modificación de las pautas de crecimiento de la población ${ }^{11}$; y no tanto por las derivadas del movimiento natural, con un saldo vegetativo claramente desfavorable, como por las que tienen que ver con unos flujos de entrada migratoria superiores, por fin, a los de salida (con un saldo positivo entre 2001 y 2011 cifrado en 391 personas; la mayoría inmigrantes extranjeros, que alcanzan su máximo en 2012, con 330 empadronados). Y es lógico suponer, en definitiva, que mientras que durante medio siglo se ha venido asistiendo a la quiebra definitiva por desvitalización demográfica del modelo de funcionamiento histórico del espacio serrano tradicional, los favorables datos actuales parecen tener que ver con la progresiva construcción de un nuevo modelo territorial: el de la inserción de esta "Sierra", anteriormente calificada como "elusiva", en la sociedad urbanizada"

Figuras 18, 19, 20 y 21. Tasas medias anuales de crecimiento acumulado de la población por periodos en los municipios del área de estudio
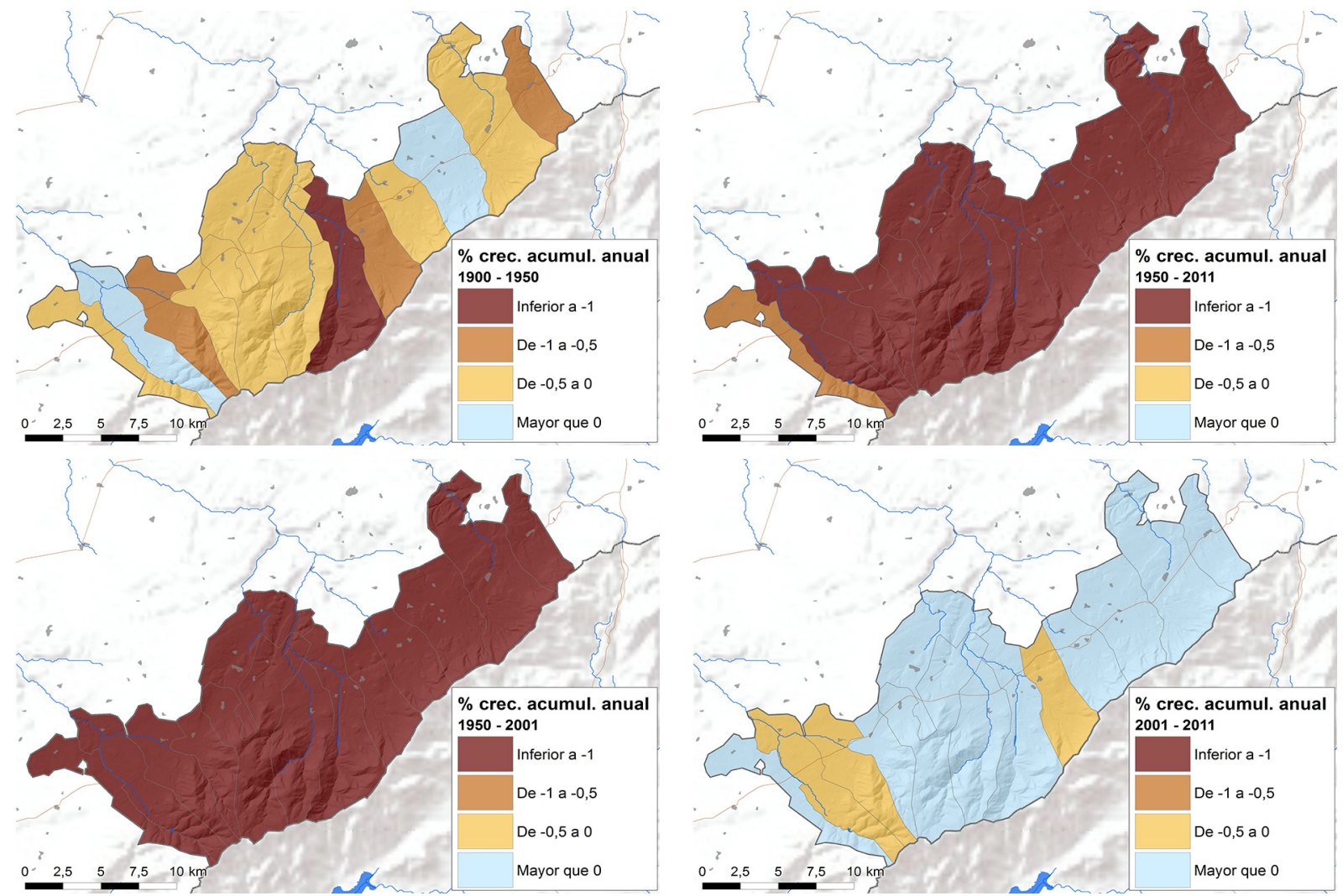

Fuente: INE: Censo de Población y Viviendas (varios años).

\subsection{Despoblación y (des)organización del modelo de poblamiento}

Como no podía ser de otro modo, la sobresaliente pérdida de población arrojada por la evolución descrita para los trece municipios serranos considerados repercute considerablemente en el grado de

11 A la espera de contar con una perspectiva temporal más amplia, que permita la confirmación de las tendencias expansivas apuntadas, estas han de tomarse con excesiva cautela, máxime en un escenario de crisis como el actual. A este respecto, se reducen a 8 más los empadronados en 2014 respecto a 2001 en el conjunto territorial, con seis de los términos municipales (Aldealengua de Pedraza, -3; Arcones, -14; Gallegos, -12; Matabuena, -31; Navafría, -41; y Santo Domingo de Pirón, -5) experimentando los balances negativos.

12 Ya atisbado por Manero Miguel en un certero diagnóstico de la realidad comarcal al señalar:

"todo parece indicar que nos encontramos en los comienzos de una nueva fase, en la que convergen los impulsos urbanos con el creciente atractivo de la comarca o el despliegue de las iniciativas que en ella tienen lugar, permitiendo ratificar las estrechas relaciones de interdependencia que en los momentos actuales -y lo que es más importante, hacia el futuro- se establecen entre los procesos demográficos, los cambios en el funcionamiento de la actividad económica y los impactos que directamente repercuten sobre el uso del suelo y la preservación de sus valores ambientales y socioculturales" (Manero, 1993, p. 20). 
ocupación del espacio. Si históricamente la relación establecida entre las comunidades serranas y el territorio se manifestaba en unas densidades poblacionales nada desdeñables, para lo que venían siendo los ámbitos montañosos (22,7 habitantes por kilómetro cuadrado, en conjunto, en 1900, y 20,1, en 1950; aun con manifiestos contrastes internos entre los diferentes términos, que para la última de las fechas citadas confrontaba a Santo Domingo de Pirón -menos de $5 \mathrm{hab} / \mathrm{km}^{2}-$, Aldealengua de Pedraza, Sotosalbos y Basardilla -menos de 15 hab/ $\mathrm{km}^{2}$ - con Arcones, Matabuena, Prádena, Navafría, Casla y Collado Hermoso -más de 20 hab/ $\mathrm{km}^{2}$-, quedando Santiuste de Pedraza, Torre Val de San Pedro y Gallegos en valores intermedios), la ruptura definitiva del sistema tradicional se dejó sentir, y de qué manera, en un abultado descenso de los índices, que se dividen prácticamente por tres a día de hoy (Figuras 22 y 23). Y es así como la despoblación, técnicamente atribuible a toda área por debajo de los los 15 habitantes por kilómetro cuadrado, es el rasgo, junto con el envejecimiento, que mejor refleja la desvitalización demográfica -y con ella la disolución social inherente a la desorganización del espacio serrano tradicional-. Y casi debiera dar igual fijarse en los casos de Prádena, Navafría o Matabuena, los únicos que en el presente superan los 10 hab $/ \mathrm{km}^{2}$, que hacerlo en los de Santo Domingo de Pirón, Aldealengua de Pedraza, Santiuste de Pedraza, Torre Val de San Pedro o Gallegos, que ni siquiera llegan a alcanzar los $5 \mathrm{hab} / \mathrm{km}^{2}$. El resultado viene a ser el de una parecida imagen de soledad o de vacío.

Figuras 22 y 23. Densidad de población en los municipios del área de estudio

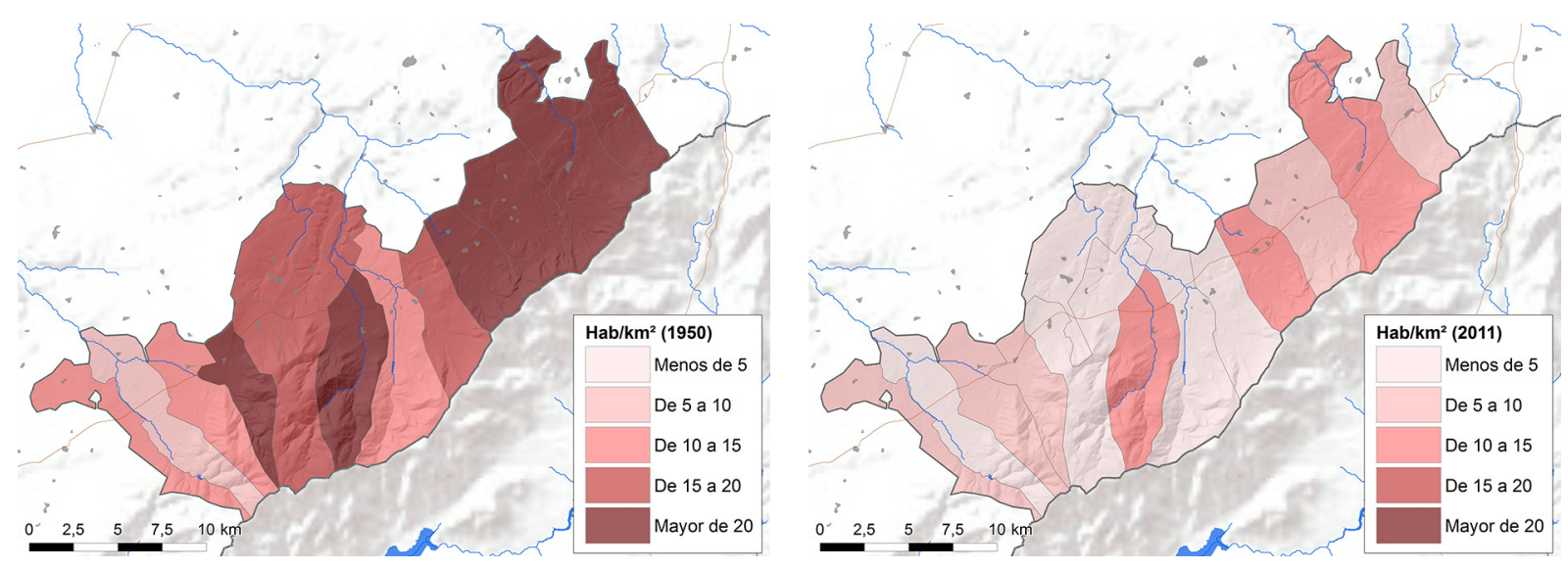

Fuente: INE: Censo de Población y Viviendas, 1950 y 2011.

Porque, más allá de estas apreciaciones realizadas a escala municipal, la aproximación a las entidades de población existentes en su seno termina de dar cuenta de la debilidad presente en el modo de ocupación del espacio. Una más que evidente relajación en las pautas de distribución espacial de la población que no puede ser puesta de manifiesto si no es por medio del análisis de todas y cada una de las entidades contenidas en el Nomenclátor. "Lugares" y "barrios" -aparte de algunos "caseríos" más dispersos- son las formas concretas del poblar, los elementos sustanciales del sistema de poblamiento tradicional ${ }^{13}$. Un rápido repaso a esta fuente estadística para los últimos sesenta años descubre el abandono -despoblamientoy la sensible contracción del tamaño de los núcleos que (des)articulan el territorio.

Partiendo de una estructura de asentamientos bastante atomizada (35 entidades de población en 1950), la idea que más claramente se desprende del diagnóstico sobre su situación actual es la que corrobora la existencia de un proceso de desarticulación irreversible de la red de poblamiento histórica (Figuras 24 y 25). Siete son las entidades despobladas por completo a lo largo del lapso temporal contemplado (La Ermita, en Aldealengua de Pedraza; Caserío de Retamal y Caserío de Majalcarro, en Navafría; Matandrino, Pradenilla y Villar, en Prádena; y Caserío de Pirón, en Sotosalbos) ${ }^{14}$. Las 28 restantes manifiestan,

13 Forman, en esencia, el tipo característico de poblamiento concentrado de raigambre medieval que García Fernández definiera como "aldea compacta con calles" (García, 2000). Es el modelo descrito por Madoz en su Diccionario. También recogido por Siguero (1997), que da cuenta, estadísticas al margen, de su significado y evolución.

14 Otras modificaciones en la estructura del poblamiento a considerar en este periodo son las de las anexiones de los núcleos de Castroserna de Arriba al municipio de Prádena, en la década de los 70, y de La Salceda a Torre Val de San Pedro, en el decenio de 1960. Igualmente, se constasta la aparición de una nueva entidad de población, denominada genéricamente como "Urbanos" (con 5 habitantes), en el término de Santiuste de Pedraza. 
por su parte, la pérdida de la funcionalidad alcanzada en el marco del sistema serrano tradicional. Si en 1950 había dos núcleos que superaban con holgura los 500 habitantes (Navafría, 717 hab, y Prádena, 971 hab), en 2014 solamente este último (y descendiendo a 547 sus residentes) lograba mantenerse en lo más alto de la jerarquía poblacional. Pérdidas de entidad mejor expresadas, si cabe, al constatar la merma de efectivos en las entidades comprendidas en 1950 entre los 250-500 habitantes y los 100-250. Nueve las primeras, que correspondían con el resto de capitales municipales ("lugares"), a excepción de las anteriores y de las de Aldealengua de Pedraza, Santiuste de Pedraza y Santo Domingo de Pirón, además del "barrio" de Huerta en Arcones; y doce las segundas: Ceguilla -la capital- y Martincano, en Aldealengua de Pedraza; Castillejo, en Arcones; Cañicosa y Matamala, en Matabuena; Castroserna de Arriba (hoy en Prádena); La Mata -la capital-, Chavida y Requijada, en Santiuste de Pedraza; Santo Domingo de Pirón; y Valle de San Pedro y La Salceda, en Torre Val de San Pedro. Por su parte, el mapa del poblamiento actual acabaría de expresar con el mayor número de aldeas y pueblos por debajo de los 100 habitantes -21, por 12 en 1950- los inequívocos síntomas del despoblamiento y la despoblación. Así, los cuatro núcleos de Aldealengua de Pedraza entran en este umbral (todos por debajo de los 50 habitantes; y dos, Galíndez y Cotanillo, no superando los 10); como los seis de Arcones (incluyendo el propio Arcones, 97 habitantes en 2014, y Huerta, 51); Gallegos (95 habitantes); Cañicosa y Matamala (23 y 18 habitantes, respectivamente), en Matabuena; Castroserna de Arriba (20 habitantes), en Prádena; Chavida, Requijada y La Mata (20, 34 y 57 residentes), en Santiuste de Pedraza; Santo Domingo de Pirón (59); y La Salceda, Valle de San Pedro y Torre Val de San Pedro (44, 60 y 89 habitantes), en Torre Val de San Pedro.

Figuras 24 y 25. Estructura del poblamiento tradicional y actual en los municipios del área de estudio
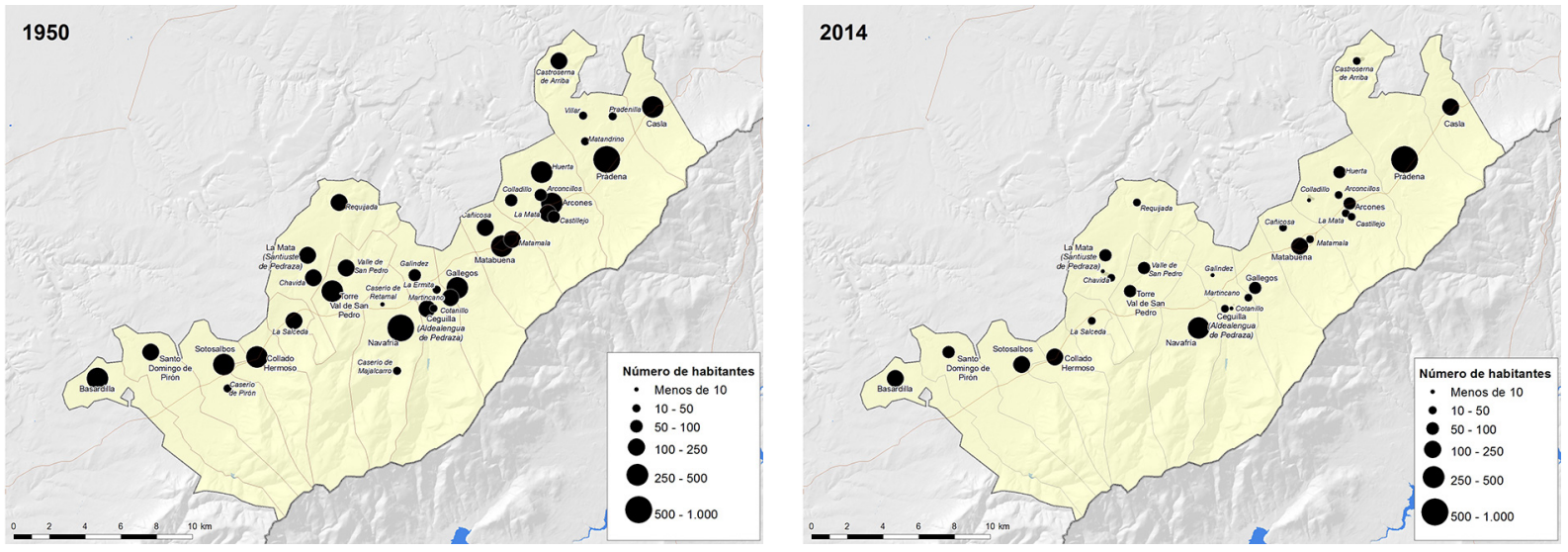

Fuente: INE: Nomenclátor de entidades de población, 1950 y 2014.

\subsection{Una población sumamente envejecida (y masculinizada) inserta en una dinámica natural regresiva}

Si la emigración ha sido la constante que ha motivado la evolución a la baja de la población residente en el espacio serrano, la despoblación se ha erigido en uno de sus atributos más remarcados. Y ambos, como consecuencias de un mismo proceso de descomposición de las bases demográficas de este sector del Guadarrama segoviano interpretado, encuentran el correlato final en el progresivo nivel de envejecimiento alcanzado por los habitantes que aún permanecen en él. La vejez constituye, de esta forma, el otro de los signos del agotamiento social. Y a este carácter senil de las estructuras etarias obedece, por último, el de un movimiento natural claramente desfavorable para las tasas de natalidad, en virtud de una mucho más elevada mortalidad, con lo que el crecimiento vegetativo resultante es sumamente negativo.

El estrechamiento en la base por el descenso del número de nacimientos, que se hace del todo extensivo hasta las cohortes de edad nacidas a mediados-finales de los años 70 , por otra parte las que englobarían a las generaciones fértiles y, por ende, con potencial capacidad reproductiva, el estrangulamiento entre los 55-75 años por la masiva emigración de los decenios de 1960 y 1970 (también la del anterior), descompensado, a su vez, a favor de los hombres, merced al mayor flujo relativo de salida femenina, y el ensanchamiento en la cúspide son los rasgos esenciales de la pirámide de población comarcal (Figura 26). 
Unas estructuras demográficas que, traducidas a datos e índices municipales, confirman los serios problemas poblacionales presentes y las expectativas futuras de este territorio serrano (Tabla 5). No en vano, quitando a Basardilla $(0,8)$, por su evidente cercanía al área urbana de Segovia, ninguno de los otros doce términos presentan un índice de envejecimiento (relación entre la población residente mayor de 65 años y la menor de 15) inferior a 1,5 (que corresponde a Sotosalbos, en el que en algo se dejan sentir los influjos periurbanos), con relaciones del todo alarmantes como las de Santiuste de Pedraza (18,7 mayores por cada jóven), Aldealengua de Pedraza (11,3) o Navafría $(6,4)$. Así, no es de extrañar que las edades medias sean del todo punto exageradas (con siete municipios superando los 50 años y uno de ellos, Santiuste de Pedraza, los 60) o las proporciones de habitantes por encima de los 80 años, salvando Basardilla (5,9\%), se sitúen por encima del 10\% (con Arcones, 18,5\%, y Navafría, 18,2\%, como situaciones extremas). En suma, atonía presente e incierto escenario el que se atisba en el horizonte como lo confirma, igualmente, el expresivo índice de reemplazo de activos (cociente entre los residentes de 15 a 19 años, es decir, la próxima cohorte de potenciales incorporados al mercado laboral, y los de 60 a 64 años, los más cercanos a la jubilación), que bien pudiera ser puesto en relación, por ejemplo, con las perspectivas de "supervivencia" de las explotaciones ganaderas, y que está asegurado solamente en 6 municipios, truncándose por completo en los restantes (con valores que oscilan desde el 0,3 de Santiuste de Pedraza al 0,8 de Prádena).

Figura 26. Pirámide de la población actual del área de estudio

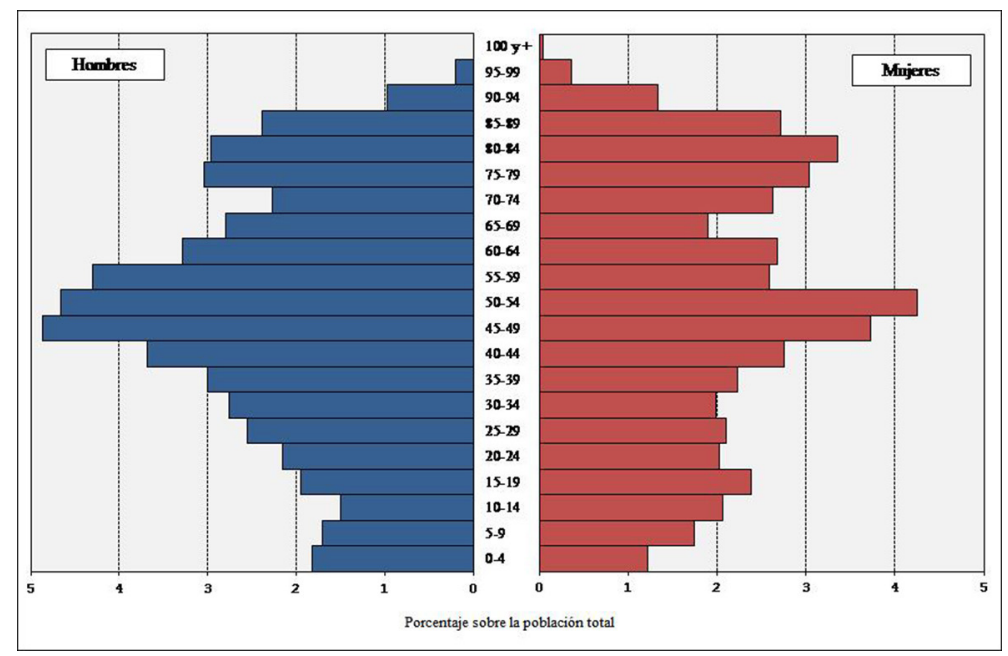

Fuente: INE: Padrón Municipal de Habitantes, 2014

Un envejecimiento tras el cual se esconden las cifras de una dinámica natural de la población totalmente regresiva. Trayendo a colación las cuantificaciones registradas por el Instituto Nacional de Estadística sobre esta cuestión (en su serie sobre Movimiento Natural de la Población), el crecimiento vegetativo para el conjunto territorial entre los años 2001 y 2011 fue de -169. Al incremento de la mortalidad, propio de un ámbito con una proporción abultadísima de personas mayores, por lo que se acaba resaltar, se le une el de una natalidad muy baja (por apuntar dos datos: en el lapso temporal 2012-2013 cuatro de los municipios no registraron nacimiento alguno -con Aldealengua de Pedraza, Basardilla, Collado Hermoso y Santo Domingo de Pirón en tasas brutas de natalidad del 0,0\%o-, llegando a ocho-Aldealengua de Pedraza, Arcones, Basardilla, Collado Hermoso, Santiuste de Pedraza, Santo Domingo de Pirón, Sotosalbos y Torre Val de San Pedro- en el último balance publicado, el 2013-2014). Lo cual no es para nada extraño, pues a una población sumamente envejecida se le une el hecho de ser una población altamente masculinizada. Los índices de feminidad mostrados son bien claros a este respecto (Tabla 5). Siendo manifiestamente desfavorables para las mujeres en los grupos de edad más proclives a la fecundidad (también todavía a la nupcialidad, con tasas del 0,0\% en Aldealengua de Pedraza, Matabuena, Navafría, Prádena, Santo Domingo de Pirón y Sotosalbos, durante 2012-2013, y en Arcones, Basardilla, Casla, Collado Hermoso, Gallegos, Matabuena, Navafría, Santo Domingo de Pirón, Sotosalbos y Torre Val de San Pedro, en 2013-2014), con solo tres municipios (Arcones, Basardilla y Sotosalbos) presentando relaciones de mujeres entre los 25 y 39 años superiores a los varones. Y este hecho, el de la masculinización, extensible, por otro lado, a la casi totalidad de las cohortes etarias ( 1,1 hombres por mujer en el conjunto), debido 
fundamentalmente a la mayor propensión, de siempre, a la emigración por parte de las mujeres, es otra de las circunstancias a tener muy en cuenta.

Tabla 5. Indicadores de estructuras demográficas en los municipios del área de estudio

\begin{tabular}{|c|c|c|c|c|c|c|}
\hline Municipio & $\begin{array}{c}\text { Índice de } \\
\text { envejecimiento }\end{array}$ & $\%$ octogenarios & Edad media & $\begin{array}{l}\text { Índice de } \\
\text { reemplazo de } \\
\text { activos }\end{array}$ & $\begin{array}{c}\text { Indice de } \\
\text { feminidad } \\
25 \text { a } 39 \text { años }\end{array}$ & $\begin{array}{c}\text { Índice de } \\
\text { feminidad } \\
65 \text { y más años }\end{array}$ \\
\hline Aldealengua de Pedraza & 11,33 & 17,98 & 57,61 & 0,40 & 0,50 & 0,61 \\
\hline Arcones & 5,12 & 18,45 & 54,20 & 0,58 & 1,35 & 1,23 \\
\hline Basardilla & 0,75 & 5,88 & 40,38 & 3,25 & 1,27 & 0,90 \\
\hline Casla & 1,73 & 12,57 & 46,81 & 1,14 & 0,53 & 1,04 \\
\hline Collado Hermoso & 2,44 & 10,46 & 48,64 & 1,38 & 0,54 & 1,31 \\
\hline Gallegos & 3,44 & 15,79 & 51,03 & 2,00 & 0,80 & 1,06 \\
\hline Matabuena & 5,90 & 13,54 & 51,04 & 1,00 & 0,61 & 1,03 \\
\hline Navafría & 6,35 & 18,18 & 54,46 & 0,36 & 0,78 & 1,03 \\
\hline Prádena & 2,04 & 14,11 & 47,61 & 0,80 & 0,67 & 1,21 \\
\hline Santiuste de Pedraza & 18,67 & 17,24 & 60,09 & 0,25 & 0,25 & 0,80 \\
\hline Santo Domingo de Pirón & 3,67 & 11,86 & 48,43 & 0,67 & 0,83 & 0,37 \\
\hline Sotosalbos & 1,50 & 10,61 & 45,83 & 1,17 & 1,83 & 0,94 \\
\hline Torre Val de San Pedro & 3,67 & 15,03 & 51,98 & 0,29 & 0,52 & 1,20 \\
\hline
\end{tabular}

Fuente: INE: Padrón Municipal de Habitantes, 2014.

\section{CONCLUSIONES}

La disolución demográfica es la expresión definitiva de la desorganización del espacio tradicional en el aquí denominado Guadarrama segoviano. Corresponde con la decadencia encontrada en la forma en que se venía ocupando el territorio por parte de las comunidades serranas. Se relaciona con el declinar de un modelo de explotación secular de los recursos que ofrecía el espacio físico: desde las peanas del piedemonte y hasta el "alto de la sierra"; toda una sucesión de ambientes "escalonados" que habían destacado por su importante función secular, como elementos plenamente incorporados al sistema de aprovechamiento ganadero. Responde, en definitiva, a los cambios habidos en la construcción del espacio.

Todo ello ha significado, en términos generales, el colofón decisivo a la quiebra del funcionamiento histórico del espacio serrano, a partir de la incidencia, sobre amplios sectores, de procesos de abandono y de prácticas de degradación. Estos son consecuencia de la "supervivencia", más que la mera pervivencia, de un modelo geográfico de corte tradicional-degradado, que aparte de implicar la sobreexplotación de los predios más apetecibles se deja sentir, sobremanera, en la simplificación del modo de manejo animal y en la dejadez de las superficies pratenses más marginales o menos aptas, lo que conlleva a la modificación del paisaje por colonización vegetal. Una "supervivencia" de la tradición, en todo caso, supeditada a esa misma disolución social.

\section{REFERENCIAS}

Cabero Diéguez, V. (2000). El carácter rural de las montañas. En E. Martínez de Pisón (Dir.), Estudios sobre el paisaje (pp. 103-119). Madrid: Universidad Autónoma de Madrid y Fundación Duques de Soria.

Cassé-Castells, $M^{a}$.C. (2001). Comment aborder la question montagnarde aujourd'hui dans les pays industrialisés d'Europe Occidentale. En Y. Veyret (Coord.), Les montagnes. Discours et enjeux géographiques (pp. 125-134). París: Sedes.

Colectivo de Investigadores sobre las Montañas Españolas (CIMA) (2005). Las montañas españolas: conceptos y vocabulario. Madrid: Entinema.

Collantes Gutiérrez, F. (2004a). La evolución de la actividad agrícola en las áreas de montaña españolas (1860-2000). Revista Española de Estudios Agrosociales y Pesqueros, (201), 135-155.

Collantes Gutiérrez, F. (2004b). El declive demográfico de la montaña española (1850-2000): ¿un drama rural? Madrid: Ministerio de Agricultura, Pesca y Alimentación.

Deffontaines, P. (1949). Contribution a une géographie humaine de la montagne. Pirineos, (11-12), 99-172. 
Delgado Viñas, C. y Plaza Gutiérrez, J.I. (Eds.) (2012). Territorio y paisaje en las montañas españolas. Estructuras y dinámicas espaciales. Santander: Librería Estvdio y Ministerio de Ciencia e Innovación.

Díez Mayoral, D. (2003). Políticas de intervención y dinámicas territoriales en las áreas del Sistema Central de Castilla y León. Madrid: Universidad Complutense de Madrid.

García Fernández, J. (2000). Geografía histórica de España. Valladolid: Universidad de Valladolid (inédito).

García Ruiz, J.Mª . (1988). La evolución de la agricultura de montaña y sus efectos sobre la dinámica del paisaje. Revista de Estudios Agrosociales, (146), 7-37.

Lasanta Martínez, T. (1990a). Tendencias en el estudio de los cambios de usos del suelo en las montañas españolas. Pirineos, (135), 7-106.

Lasanta Martínez, T. (1990b). Tendences actuelles de l'organisation spatial des montagnes espagnoles. Annales de Géographie, (551), 51-71.

Lasanta Martínez, T., Nadal Romero, Mª.E., Gómez Villar, A. y Serrano Muela, Mª.P. (2014). Los estudios sobre cambios de gestión y ocupación del suelo en la montaña española cuarenta años después. En J. Arnáez Vadillo, P. González Sampériz, T. Lasanta Martínez y B.L. Valero Garcés (Eds.), Geoecología, cambio ambiental y paisaje: homenaje al profesor José María García Ruiz (pp. 383-394). Logroño: Consejo Superior de Investigaciones Científicas y Universidad de La Rioja.

Madoz, P. (Ed. fac., 1998). Diccionario Geográfico-Estadístico-Histórico de España y sus posesiones de ultramar. 1845-1850. Valladolid: Ámbito.

Manero Miguel, F. (1993). Bases socioeconómicas (monografía 2). En L.F. Alonso Teixidor (Dir.), Plan Especial de la Sierra de Guadarrama. T. 3 (pp. 1-77). Valladolid: Consejería de Medio Ambiente y Ordenación del Territorio de la Junta de Castilla y León.

Martínez Fernández, L.C. y Molina de la Torre, I. (2015). Docencia e investigación a través del análisis y la fotointerpretación del territorio. Los paisajes del Guadarrama (Segovia). Ería, (98), 309-326.

Mata Olmo, R. y Sanz Herráiz, C. (Dirs.) (2004). Atlas de los paisajes de España. Madrid: Ministerio de Medio Ambiente.

Montiel Molina, C. (2003). Tradición, renovación e innovación de los usos y aprovechamientos en las áreas rurales de montaña. Cuadernos Geográficos, (33), 7-26.

Ortega Valcárcel, J. (1989). La economía de montaña una economía de equilibrio. Ería, (19-20), 115-128.

Ortega Valcárcel, J. (2000). Los horizontes de la Geografía. Teoría de la Geografía. Barcelona: Ariel.

Ortega Valcárcel, J. (2004). Áreas de montaña: de la supervivencia a la integración. Boletín de la A.G.E., (38), 5-28.

Plaza Gutiérrez, J.I. (2008). Las áreas de montaña en España: balance sobre su investigación y su tratamiento en los últimos quince años. Ería, (75), 5-25.

Plaza Gutiérrez, J.I. (Coord.) (2008). Las áreas de montaña: caracterización, desarrollo y transformaciones. Polígonos, (18), 9-257.

Sacareau, I. (2003). La montagne, Une approche géographique. París: Éditions Belin.

Siguero Llorente, P. (1997). Significado de los nombres de los pueblos y despoblados de Segovia. Madrid: A.G. Gavilán.

Tanarro García, L.M. (1994). Transformación y progresiva integración de un municipio de montaña: Prádena de la Sierra, Guadarrama oriental (Segovia). Anales de Geografía de la Universidad Complutense, (14), 177-208.

Tanarro García, L.M. (1996). Transformaciones socioeconómicas y dinámica del paisaje rural en la vertiente norte de la Sierra de Guadarrama: el ejemplo de los valles de los ríos San Juan y Caslilla (afluentes al Duratón, Segovia). En La conservación del paisaje rural. Nuestros sistemas agrarios tradicionales: valores, problemática y futuro. Actas de las VIII Jornadas sobre el paisaje (pp. 195-210). Segovia: Asociación para el Estudio del Paisaje.

Troitiño Vinuesa, M.A. (1990). El Sistema Central. En A. Cabo Alonso y F. Manero Miguel (Dirs.), Geografía de Castilla y León, T. 8 (pp. 76-139). Valladolid: Ámbito.

Vías, J. (2014). Paque Nacional de la Sierra de Guadarrama. Guía para contemplar su paisaje. Madrid: Ediciones La Librería. 